\title{
The stratification of primary Sjogren's syndrome: is it really solving the problem?
}

\author{
Cristian Baicus ${ }^{1}$ (D)
}

Received: 23 July 2021 / Accepted: 27 July 2021 / Published online: 11 August 2021

(c) The Author(s), under exclusive licence to Springer-Verlag GmbH Germany, part of Springer Nature 2021

\section{Dear Editor,}

I read with interest the paper of Collins et al. concerning the reanalysis of the JOQUER trial using the four pathobiological groups of patients with Sjogren's syndrome [1]. This division of Sjogren in four phenotypes could solve the problem of complexity and heterogeneity which complicates the choice of an appropriate outcome. These phenotypes were obtained by statistical means, and were possibly confirmed by the differences found between these groups concerning biological, including transcriptional, determinations, and validated on two independent cohorts of patients [2].

Reanalyzing the results of the JOQUER trial, it was shown that hydroxychloroquine might be effective in both subgroups of patients with high and low symptom burden, and not effective in the subgroups of pain dominant, and dryness dominant with fatigue patients.

The discovery of these subgroups could be an important step ahead for the clinical management and trial design concerning the patients with Sjogren's syndrome. However, the efficacy of the drug both in the high burden, and low burden symptoms group is counterintuitive, and the most probable explanation is chance. Moreover, the previous reanalysis of the same trial, using the same subgroups, but in another article [2] found effectiveness only in the high symptom burden group.

The reanalysis showed that, in the high symptom burden group, the relative improvement of ESSPRI between hydroxychloroquine and placebo at 24 months was of 1.49 points (95\% CI 0.54-2.43). This is a statistically significant difference. However, the authors did not demonstrate that the difference was clinically significant, too, as the minimally important difference of 1 point on ESSPRI [3] was inside the confidence interval.

Thus, there still is a long way to go until the possible validation of this stratification.

\section{References}

1. Collins A, Lendrem D, Wason J et al (2021) Revisiting the JOQUER trial: stratification of primary Sjögren's syndrome and the clinical and interferon response to hydroxychloroquine. Rheumatol Int 41:1593-1600. https://doi.org/10.1007/ s00296-021-04927-y

2. Tarn JR, Howard-Tripp N, Lendrem DW et al (2019) Symptombased stratification of patients with primary Sjögren's syndrome: multi-dimensional characterisation of international observational cohorts and reanalyses of randomised clinical trials. Lancet Rheumatol 1:e85-e94. https://doi.org/10.1016/S2665-9913(19)30042-6

3. Seror R, Bootsma H, Saraux A et al (2016) Defining disease activity states and clinically meaningful improvement in primary Sjögren's syndrome with EULAR primary Sjögren's syndrome disease activity (ESSDAI) and patient-reported indexes (ESSPRI). Ann Rheum Dis 75:382-389. https://doi.org/10.1136/annrh eumdis-2014-206008

Publisher's Note Springer Nature remains neutral with regard to jurisdictional claims in published maps and institutional affiliations.

This comment refers to the article available online at https://doi. org/10.1007/s00296-021-04927-y.

Cristian Baicus

cristian.baicus@umfcd.ro

1 Department of Internal Medicine, Colentina University

Hospital Bucharest, Carol Davila University of Medicine

and Pharmacy, 020125 Bucharest, Romania 